\title{
(2) OPEN ACCESS \\ Evaluation of community coalition training effects on youth hospital-admitted injury incidence in Victoria, Australia: 2001-2017
}

\author{
Janneke Berecki-Gisolf $\odot$, ${ }^{1}$ Bosco Rowland, ${ }^{2}$ Nicola Reavley, ${ }^{3}$ Barbara Minuzzo, ${ }^{4}$ \\ John Toumbourou ${ }^{2,5}$
}

\begin{abstract}
- Additional material is published online only. To view please visit the journal online (http://dx.doi.org/10.1136/ injuryprev-2019-043386).

${ }^{1}$ Monash University Accident Research Centre, Monash University, Clayton, Victoria, Australia

${ }^{2}$ Faculty of Health, Deakin University, Geelong, Victoria, Australia

${ }^{3}$ Centre for Mental Health, The University of Melbourne School of Population and Global Health, Melbourne, Victoria, Australia

${ }^{4}$ Communities That Care Ltd, Parkville, Victoria, Australia ${ }^{5}$ Centre for Adolescent Health, Murdoch Children's Research Institute, Royal Children's Hospital, Parkville, Victoria, Australia
\end{abstract}

\section{Correspondence to} Dr Janneke Berecki-Gisolf, Monash University Accident Research Centre, Monash University, Clayton, VIC 3800, Australia; janneke.bereckigisolf@monash.edu

Received 11 July 2019 Revised 20 September 2019 Accepted 23 September 2019 Published Online First 21 November 2019

Check for updates

\section{(C) Author(s) (or their} employer(s)) 2020. Re-use permitted under CC BY-NC. No commercial re-use. See rights and permissions. Published by BMJ.

To cite: Berecki-Gisolf J, Rowland B, Reavley N, et al. Inj Prev 2020;26:463-470.

\begin{abstract}
Background Injuries are one of the three leading causes of morbidity and mortality for young people internationally. Although community risk factors are modifiable causes of youth injury, there has been limited evaluation of community interventions. Communities That Care (CTC) offers a coalition training process to increase evidence-based practices that reduce youth injury risk factors.
\end{abstract}

Method Using a non-experimental design, this study made use of population-based hospital admissions data to evaluate the impact on injuries for 15 communities that implemented CTC between 2001 and 2017 in Victoria, Australia. Negative binomial regression models evaluated trends in injury admissions (all, unintentional and transport), comparing CTC and non-CTC communities across different age groups.

Results Statistically significant relative reductions in all hospital injury admissions in 0-4 year olds were associated with communities completing the CTC process and in 0-19year olds when communities began their second cycle of CTC. When analysed by subgroup, a similar pattern was observed with unintentional injuries but not with transport injuries.

Conclusion The findings support CTC coalition training as an intervention strategy for preventing youth hospital injury admissions. However, future studies should consider stronger research designs, confirm findings in different community contexts, use other data sources and evaluate intervention mechanisms.

\section{INTRODUCTION}

Commonly defined as any intentional or unintentional damage to the body, injuries are one of the three leading causes of morbidity and mortality in young people. ${ }^{1}$ Road and traffic injuries are the most common cause of death for children between ages 10-14 and 15-19 years, respectively. ${ }^{1}$ Internationally and in Australia, injury rates are increasing. ${ }^{12}$ In addition to physical consequences, injuries have a flow-on effect on the healthcare and welfare systems, through increased health service needs and reduced work capacity, respectively. Given the prevalence and consequences, it is important to implement and evaluate public health interventions to reduce injuries. ${ }^{3}$ If the negative sequelae of injuries are to be reduced, implementing and evaluating public health interventions that identify and reduce modifiable risk factors that prevent injuries in young people should be a public health priority. ${ }^{4}$

While many interventions focus on reducing proximal safety hazards, a wide range of distal risk factors for injuries in children and young people have been identified. ${ }^{3}$ Prominent examples include: socioeconomic disadvantage, ${ }^{5} 6$ community hazards, ${ }^{7}$ community violence, ${ }^{8}$ poor parenting skills, ${ }^{9}$ child behaviour problems, ${ }^{10}$ alcohol and other drug use ${ }^{11}$ and peer violence. ${ }^{6}$ Alcohol and other drug use are among the major modifiable risk factors for injury for young people. ${ }^{6}{ }^{12-14}$ Significant reductions in youth injuries have been associated with policies that restrict the availability of alcohol. ${ }^{14-17}$ Dominant community interventions, namely the WHO 'safe community' approach to coordinating community efforts to enhance safety and reduce injury, have not shown consistent injury prevention effects, potentially due to the limited risk factors they target. ${ }^{18}$

In the late 1990 s, Australia observed rising rates of adolescent health risk behaviour problems associated with drug and alcohol use. Cross-national comparisons indicated that the Australian rate of adolescent alcohol and other drug use was twice as high as the same-aged peers in the USA. ${ }^{19} 20$ In this context, it was considered important to investigate whether there were feasible and effective community-led intervention alternatives to reduce adolescent alcohol and drug use. A number of studies in that period recommended the implementation of Communities That Care (CTC) as a means of improving adolescent health. ${ }^{21-23}$

Developed in the USA, CTC is a framework to guide community coalitions to improve child and adolescent health using an evidence-based prevention approach. ${ }^{1724-26}$ The framework is organised into five standardised phases: phase 1 : recruitment and orientation of community leaders and stakeholders to the CTC process; phase 2: formation of a local coalition to guide decision making; phase 3: use of epidemiological data to prioritise risk factors and protective factors (that modify the effect of risk factors, for example, community opportunities and bonds) to be targeted for preventive action; phase 4: selection of appropriate evidence-based intervention programmes targeting identified risk and protective factors and behaviours; and phase 5: implementation, monitoring and evaluation of selected programmes on 
Table 1 Communities That Care programme roll-out in Victoria: timing of phases 1-5 (completion) and 6 (second cycle)

\begin{tabular}{lrrrrrrrrrrrrrrrrrrr}
\hline Year & 2001 & 2002 & 2003 & 2004 & 2005 & 2006 & 2007 & 2008 & 2009 & 2010 & 2011 & 2012 & 2013 & 2014 & 2015 & 2016 & 2017 \\
\hline Alpine & 0 & 0 & 0 & 0 & 0 & 0 & 0 & 0 & 1 & 2 & 3 & 4 & 5 & 5 & 5 & 6 & 6 \\
Ballarat & 2 & 3 & 4 & 5 & 5 & 5 & 5 & 5 & 5 & 5 & 5 & 5 & 5 & 5 & 5 & 5 & 5 \\
Baw Baw & 0 & 0 & 0 & 0 & 0 & 0 & 0 & 0 & 0 & 0 & 0 & 0 & 0 & 0 & 0 & 0 & 1 \\
Cardinia & 0 & 0 & 0 & 0 & 0 & 0 & 0 & 0 & 0 & 0 & 0 & 0 & 0 & 1 & 5 & 5 & 5 \\
Colac-Otway & 0 & 0 & 0 & 0 & 0 & 0 & 0 & 0 & 0 & 0 & 0 & 0 & 0 & 0 & 0 & 0 & 1 \\
East Gippsland & 0 & 0 & 0 & 0 & 0 & 0 & 0 & 0 & 0 & 0 & 0 & 0 & 0 & 0 & 3 & 5 & 5 \\
Glenelg & 0 & 0 & 0 & 0 & 0 & 0 & 0 & 0 & 0 & 0 & 0 & 0 & 1 & 2 & 3 & 3 & 3 \\
Greater Bendigo & 0 & 0 & 0 & 0 & 0 & 0 & 0 & 0 & 0 & 0 & 0 & 0 & 0 & 0 & 2 & 4 & 5 \\
Greater Geelong & 0 & 0 & 0 & 0 & 0 & 0 & 0 & 0 & 0 & 0 & 1 & 1 & 1 & 2 & 3 & 4 & 5 \\
Hobsons Bay & 0 & 0 & 0 & 0 & 0 & 0 & 0 & 0 & 0 & 0 & 0 & 0 & 0 & 0 & 0 & 1 & 2 \\
Knox & 0 & 0 & 0 & 0 & 0 & 0 & 0 & 0 & 0 & 0 & 0 & 0 & 1 & 2 & 3 & 4 & 5 \\
Mornington Peninsula & 2 & 3 & 4 & 5 & 5 & 6 & 6 & 6 & 6 & 6 & 6 & 6 & 6 & 6 & 6 & 6 & 6 \\
Stonnington & 0 & 0 & 0 & 0 & 0 & 0 & 0 & 0 & 0 & 0 & 0 & 0 & 0 & 0 & 0 & 3 & 4 \\
Warrnambool & 0 & 0 & 0 & 0 & 0 & 0 & 0 & 0 & 0 & 0 & 0 & 0 & 0 & 1 & 5 & 5 & 5 \\
Yarra & 0 & 0 & 0 & 0 & 0 & 0 & 0 & 0 & 0 & 0 & 0 & 0 & 0 & 1 & 2 & 3 & 4 \\
\hline
\end{tabular}

1=phase 1: 'Getting started'; $2=$ phase 2: 'Getting organised'; 3=phase 3: 'Developing a profile'; 4=phase 4: 'Create a plan'; 5=phase 5: 'Implement and evaluate'; 6=phase 6: second cycle.

targeted risk factors and behaviours. After a cycle is complete, based on their local data, a community can choose to repeat the five phases, either focusing on the same risk and protective factors and outcome behaviours or the community may identify new priorities (described below as phase 6).

Currently in Australia, there are 18 communities that have used the CTC framework. Pilot evaluations have indicated reductions in adolescent injury risk factors including alcohol and other drug use and behaviour problems. ${ }^{24}$ Although prior studies have evaluated CTC for impacts on injury risk factors, there have been no prior studies examining effects on injury. The aim of the present study was to determine the effect of the CTC approach on hospital-treated injury incidence among children and adolescents. In keeping with the theory of the CTC framework, ${ }^{25}$ it was hypothesised that the greatest beneficial effects would be observed at the end of one full cycle of CTC implementation (phase 5).

\section{Method}

Participating communities

Fifteen Victorian communities using the CTC framework were included in the study (table 1 ). These were both regional $(n=10)$ and major city communities $(n=5)$. More detailed information about the communities that participated in the CTC programme has been given previously ${ }^{24}$; summary statistics of the local government areas are provided in the online supplementary appendix table A1. An overview of the recruitment and phases implemented in participating communities, between 2001 and 2017, is provided in table 1. During the data collection period, completion of one full cycle of the CTC framework (phase 5), was achieved by nine municipalities. Two municipalities reached phase 6 , the second cycle, and this was achieved from 2006.

\section{Hospital admission injury data}

Hospital admission injury data were obtained through the Victorian Injury Surveillance Unit at the Monash University Accident Research Centre. Data were population-based injury hospital admissions data, which is part of the Victorian Admitted Episodes Dataset (VAED). The VAED is a state-wide collection of data pertaining to admissions to Victorian hospitals (public and private); the VAED was established in July 1987. Data are coded to the International Classification of Diseases, Australian Modification (ICD-10-AM).

Hospital admission injury data were collected at the Statistical Area Level 2 (SA2; based on the area of residence of the person admitted to hospital) in Victoria and included public and private hospitals. SA2 areas are defined based on suburb and locality boundaries to represent communities that interact together socially and economically. ${ }^{27}$ These data were used to calculate annual per capita injury rates and trends at the SA2 level; injury rates were also grouped into three subcategories: all injury admissions; unintentional injuries; and transport injuries (injury admissions with ICD-10-AM cause coded as transport: V00-V99). Sensitivity analyses were run for unintentional injuries, with sport-related injuries removed in a comparative model, to evaluate the possible effects of increased sports participation (ie, unmeasured changes in exposure).

\section{Hospital injury time period}

To align with implementation of CTC in the 15 communities, injury admissions were selected as admissions between 1 January 2001 and 31 December 2017. Only data with an injury code as the first diagnosis were used. This included all 'community acquired' injuries (ICD-10-AM codes S00T75 or T79) but not medical/surgical injuries. In children aged up to 14 years, injury admissions are mostly due to falls $(47 \%)$, hit/struck/crush injuries (17\%), transport (9\%) and cutting/piercing injuries (5\%). ${ }^{28}$ Only incident cases were selected; that is, cases were excluded where they referenced a follow-up visit or transfer to another unit within the same hospital or to another hospital. Patients who were not Victorian residents were excluded. As the study was focused on youth injury rates, persons aged 35 years and over were excluded; the 20-34 year age group was not of direct interest in this study but included as a reference group to account for fluctuations in hospital admissions due to factors unrelated to the CTC programme (eg, state policies and national economic trends). 


\section{Matching injury data and CTC phase implementation}

Data on the timing, progress and the implementation of CTC phases for the 15 communities using the CTC framework were provided to the Monash University Accident Research Centre prior to the analysis (shown in table 1). Injury trend data at the municipal level, for the years 2001-2017, were linked to the respective CTC community and stage of phase implementation.

\section{Primary study outcomes}

There were three primary outcomes of the study. These were municipal (SA2) rates of hospital admission for all injury, unintentional injury and transport injury. Rates were calculated as the annual number of injury admissions per 100000 persons.

\section{Control variables}

Factors controlled, at the SA2 level, in the analysis were community socioeconomic status based on the Australian Bureau of Statistics (ABS) 2011 population Census data ${ }^{29}$ and remoteness (based on the Australian Statistical Geography Standard). ${ }^{30}$ Victorian residential population data was used to calculate injury rates per population. This was obtained from the ABS. The data were stratified by calendar year, SA2, age in 5 -year bands and sex.

\section{Comparison communities}

To determine the effect of the CTC programme on youth hospital injury admission rates, non-participating communities were the comparison group. This included all of the State of Victoria: participating communities at baseline (phase 0) were combined with non-participating communities to form the comparison group. Only those aged $0-34$ years were included in the analysis.

\section{Analytical strategy}

The analyses were carried out using SAS software, V.9.4. To examine the effect of the implementation of CTC on youth hospital injury admission rates, CTC phase implementation was coded as follows: phase 0 was allocated to baseline, as outlined above. Phases 1-4 represented the respective phases of implementation of the CTC framework (described above). Phase 5 represented the implementation stage for one full cycle of the CTC framework; phase 6 represented the beginning of a second cycle of CTC implementation.

Unadjusted rates of hospital injuries, between 2001 and 2017, were computed first. This was done for the whole of the State of Victoria and broken down by age group. Rates were also calculated by age group and CTC phase implementation stage. The effect of the CTC programme on admitted injury rates in each SA2 over time was then determined, using negative binomial modelling. The unit of analysis was SA2 areas in Victoria: SA2 areas were specified in the 'repeated subject' statement of the model (Proc Genmod, SAS). The outcome of the model was the number of injury admissions in the SA2. Injury admission trends are impacted by hospital admission policy changes and other data artefacts. Therefore, the relative effect of the CTC on children (vs adults) was analysed. An interaction term of phase and age group was introduced to determine the relative effect of CTC on different child age groups; this interaction term was the key explanatory variable. The effect sizes of the interaction terms are exponentiated to generate IRRs. For this, the 20-35 year age group served as a reference group to account for nonCTC-related fluctuations in hospital admission rates. Control variables were calendar year (categorical variable), age group, sex, community disadvantage and remoteness. Repeated measures were used to account for repeated (yearly) trends in rates of the primary outcome in each SA2. The model was offset with the log of the population in the SA2.

\section{Sensitivity analysis}

To further verify the results of the analysis, several additional analyses were carried out. First, sports injury were included in the unintentional injury data. In the main analysis, sports were taken out as these could reflect an increase in sports participation, which is a favourable outcome. The effect of this is examined by reanalysing the unintentional injury data with sports injury included. Second, the unintentional injury modelling was rerun, including only municipalities that participated in the CTC programme, regardless of whether they reached phase 5 during the study period. This analysis tested the effect of including Victorian municipalities that did not participate in the CTC in the baseline data. Third, the analysis was rerun using medical injuries as outcome, instead of community injuries. Medical injuries are extracted as admissions with a firstlisted ICD-10-AM diagnosis code in the range of T80-T88: 'Complications of surgical and medical care, not elsewhere classified'. One would expect the CTC programme to have no effect on the incidence of medical injuries. Finally, the analysis was rerun on a combined dataset of medical and community injury data: the effect of the CTC on injuries was measured as the interaction effect between injury type (medical vs community) and CTC participation phase. It was expected that phases 5 and 6 were associated with a relative reduction in community injuries.

\section{RESULTS}

Table 2 presents unadjusted annual injury admissions from 2001 to 2017 for the whole of Victoria, between the ages of 0 and 34 years. For each age group, over the 17 -year period, the number of injuries were greater in 2017, compared with 2001. However, for all age groups, it should be noted that there was a sharp decrease in injury admissions in 2013; this coincides with a Victorian hospital admissions policy change impacting on which types of admissions are captured in these data. ${ }^{31}$ Between 2001 and 2017, unadjusted injury admission rates remained relatively stable in the age groups $0-4,5-9,10-14$ and $15-19$ years. However, there was a decrease in admission rates for the 20-34 year age group.

Table 3 presents an overview of unadjusted injury admission cases, and rates per 100000 of the population for each CTC phase, and broken down by age group. These rates show trend increases from phase 0 onwards, with a slight trend for reduced rates at phase 5 in $0-14$ year age groups.

The unadjusted crude admission rate for communities categorised at phase 0 (not having implemented CTC project) was 1433 annual injury admissions per 100000 (100k) population; this is the average across the full age range (0-34 years). In contrast, the unadjusted rates were greater in CTC implementation phase 5 (1694 injury admissions per 100000$)$ and phase 6 (2097 injury admissions per 100 000) on average across all age groups.

The results of adjusted multivariate modelling are shown in table 4 for all injury admissions, unintentional injuries and transport injuries. Values represent the incident rate ratios: 


\section{Original research}

Table 2 Overview of age-group specific injury admissions and rates, for ages 0-34 years, Victoria 2001-2017

\begin{tabular}{|c|c|c|c|c|}
\hline Age group & Year & Population & Injury admissions & $\begin{array}{l}\text { Annual injury admissions rate } \\
\text { per } 100000 \text { population }\end{array}$ \\
\hline \multirow[t]{9}{*}{$0-4$ years } & 2001 & 305843 & 3819 & 1249 \\
\hline & 2003 & 304770 & 3871 & 1270 \\
\hline & 2005 & 308110 & 3948 & 1281 \\
\hline & 2007 & 322116 & 3929 & 1220 \\
\hline & 2009 & 341658 & 4056 & 1187 \\
\hline & 2011 & 351951 & 4570 & 1298 \\
\hline & 2013 & 372996 & 3625 & 972 \\
\hline & 2015 & 388692 & 4697 & 1208 \\
\hline & 2017 & 407483 & 5062 & 1242 \\
\hline Mean 0-4years & 2001-2017 & 5854664 & 70466 & 1204 \\
\hline \multirow[t]{9}{*}{ 5-9years } & 2001 & 323793 & 3854 & 1190 \\
\hline & 2003 & 320954 & 3845 & 1198 \\
\hline & 2005 & 317273 & 3987 & 1257 \\
\hline & 2007 & 317490 & 3895 & 1227 \\
\hline & 2009 & 322017 & 3652 & 1134 \\
\hline & 2011 & 332729 & 4255 & 1279 \\
\hline & 2013 & 352461 & 3486 & 989 \\
\hline & 2015 & 375964 & 4272 & 1136 \\
\hline & 2017 & 395419 & 4550 & 1151 \\
\hline Mean 5-9years & 2001-2017 & 5753676 & 67176 & 1168 \\
\hline \multirow[t]{9}{*}{ 10-14years } & 2001 & 323192 & 4096 & 1267 \\
\hline & 2003 & 329875 & 4156 & 1260 \\
\hline & 2005 & 332993 & 4434 & 1332 \\
\hline & 2007 & 332172 & 4563 & 1374 \\
\hline & 2009 & 331234 & 4324 & 1305 \\
\hline & 2011 & 330056 & 4800 & 1454 \\
\hline & 2013 & 334698 & 3683 & 1100 \\
\hline & 2015 & 343096 & 4390 & 1280 \\
\hline & 2017 & 363600 & 5029 & 1383 \\
\hline Mean 10-14years & 2001-2017 & 5695416 & 74109 & 1301 \\
\hline \multirow[t]{9}{*}{ 15-19years } & 2001 & 322875 & 6059 & 1877 \\
\hline & 2003 & 331019 & 6089 & 1839 \\
\hline & 2005 & 338499 & 6888 & 2035 \\
\hline & 2007 & 348980 & 7276 & 2085 \\
\hline & 2009 & 359008 & 7634 & 2126 \\
\hline & 2011 & 354583 & 8106 & 2286 \\
\hline & 2013 & 361250 & 5802 & 1606 \\
\hline & 2015 & 368010 & 6576 & 1787 \\
\hline & 2017 & 374125 & 7717 & 2063 \\
\hline Mean 15-19years & 2001-2017 & 5969159 & 117569 & 1970 \\
\hline \multirow[t]{9}{*}{ 20-34years } & 2001 & 1044041 & 18157 & 1739 \\
\hline & 2003 & 1061126 & 16844 & 1587 \\
\hline & 2005 & 1073797 & 18207 & 1696 \\
\hline & 2007 & 1103825 & 19174 & 1737 \\
\hline & 2009 & 1181283 & 19429 & 1645 \\
\hline & 2011 & 1229059 & 22053 & 1794 \\
\hline & 2013 & 1292876 & 16877 & 1305 \\
\hline & 2015 & 1366380 & 19884 & 1455 \\
\hline & 2017 & 1457814 & 22644 & 1553 \\
\hline Mean 20-34 years & 2001-2017 & 20356470 & 325898 & 1601 \\
\hline
\end{tabular}

Bold values provide the results for the age group, across the period 2001-2017.

the effect sizes of the interaction terms are exponentiated to generate these. Values less than 1 indicate a decrease, compared with the reference group; values greater than 1 represent an increase, compared with the reference group.
Statistical significance $(\mathrm{p}<0.05)$ is indicated in bold type. Table 4 only shows the interaction effect: the full model and the univariate models are given in the online supplementary appendix, table A2. 
Table 3 Injury admission rates per age group, per Communities That Care (CTC) implementation phase, Victoria 2001-2017

\begin{tabular}{|c|c|c|c|c|}
\hline $\begin{array}{l}\text { Age group } \\
\text { (years) }\end{array}$ & CTC phase & Population & $\begin{array}{l}\text { Injury } \\
\text { admissions }\end{array}$ & $\begin{array}{l}\text { Annual injury } \\
\text { admissions } \\
\text { rate per } \\
100000 \\
\text { population }\end{array}$ \\
\hline \multirow[t]{7}{*}{$0-4$ years } & 0 (baseline ${ }^{*}$ ) & 5362544 & 64061 & 1195 \\
\hline & 1 & 70270 & 963 & 1370 \\
\hline & 2 & 53172 & 651 & 1224 \\
\hline & 3 & 50378 & 627 & 1245 \\
\hline & 4 & 52178 & 703 & 1347 \\
\hline & 5 & 162137 & 2012 & 1241 \\
\hline & 6 & 103985 & 1449 & 1393 \\
\hline \multirow[t]{7}{*}{ 5-9years } & 0 (baseline ${ }^{*}$ ) & 5256626 & 60694 & 1155 \\
\hline & 1 & 66930 & 863 & 1289 \\
\hline & 2 & 52454 & 602 & 1148 \\
\hline & 3 & 50634 & 624 & 1232 \\
\hline & 4 & 52075 & 685 & 1315 \\
\hline & 5 & 160890 & 1942 & 1207 \\
\hline & 6 & 114067 & 1766 & 1548 \\
\hline \multirow[t]{7}{*}{ 10-14years } & 0 (baseline ${ }^{\star}$ ) & 5207596 & 66712 & 1281 \\
\hline & 1 & 64721 & 951 & 1469 \\
\hline & 2 & 50528 & 658 & 1302 \\
\hline & 3 & 50549 & 731 & 1446 \\
\hline & 4 & 50656 & 732 & 1445 \\
\hline & 5 & 158025 & 2239 & 1417 \\
\hline & 6 & 113341 & 2086 & 1840 \\
\hline \multirow[t]{7}{*}{ 15-19years } & 0 (baseline $^{*}$ ) & 5455125 & 105911 & 1942 \\
\hline & 1 & 70533 & 1536 & 2178 \\
\hline & 2 & 53161 & 993 & 1868 \\
\hline & 3 & 53321 & 1069 & 2005 \\
\hline & 4 & 53642 & 1127 & 2101 \\
\hline & 5 & 169074 & 3841 & 2272 \\
\hline & 6 & 114303 & 3092 & 2705 \\
\hline \multirow[t]{7}{*}{ 20-34 years } & 0 (baseline ${ }^{*}$ ) & 18768138 & 296198 & 1578 \\
\hline & 1 & 235641 & 4209 & 1786 \\
\hline & 2 & 184824 & 3015 & 1631 \\
\hline & 3 & 198950 & 3203 & 1610 \\
\hline & 4 & 209606 & 3400 & 1622 \\
\hline & 5 & 492303 & 9320 & 1893 \\
\hline & 6 & 267008 & 6553 & 2454 \\
\hline
\end{tabular}

1=phase 1: 'Getting started'; $2=$ phase 2: 'Getting organised'; $3=$ phase 3:

'Developing a profile'; 4=phase 4: 'Create a plan'; $5=$ =phase 5: 'Implement and evaluate'; $6=$ phase 6 : second cycle.

*Baseline includes non-participating municipalities as well as participating municipalities, prior to the CTC programme.

\section{All injury admissions}

Compared with the age group of 20-34 years, statistically significant reductions in 'all injury' admissions were observed at phase 5 CTC for age groups $0-4$ years (RR 0.88; 95 CI 0.79 to 0.98$)$ ) only. There were non-significant reductions in the age groups 5-9, 10-14 and 15-19 years, compared with the 20-34 age group. Statistically significant relative reductions in injury admissions were observed in phase 6 ; in all age groups $(0-19$ years, compared with 20-34 years).

\section{Unintentional injuries}

Statistically significant relative reductions in unintentional injury admissions (sports-related injuries excluded) were observed in the age group $0-4,5$ years at CTC phase 5 , compared with the 20-34 age group. Statistically significant reductions were observed in all age groups (0 to 19 years) when a community was in phase 6 (implementing a new cycle of CTC).

\section{Transport injuries}

There were no clear patterns of association between CTC implementation (phase 5) and rates of transport-related injury admissions in the age groups analysed. In the second cycle (phase 6), a relative reduction was observed in age groups $0-4$ and 5-9 years. The age group 15-19 years, however, showed a (non-significant) increase in injury admission rates at phase 6, compared with the age group 20-35 years.

\section{Sensitivity analysis}

Analysing a combined dataset of medical injuries and community injuries, there was a statistically significant interaction effect between injury type (community vs medical) and CTC phase, adjusting for age, sex, socioeconomic index for area, remoteness and year (table 5). Phase 5 (vs phase 0 ) was associated with a significant relative reduction in community injuries versus medical injuries.

The unintentional injury model, including sports injury, is very similar to the model of unintentional injury with sports injuries excluded: results are shown in the online supplementary appendix table A3. Including only communities that participated in the CTC programme resulted in a stronger injury reductive effect of CTC completion: this effect was statistically significant in age groups 0-14 years, compared with the 20-34 year age group. Phase 6 was also associated with a relative reduction in injury admissions per population in this model (online supplementary appendix, table A4).

The effect of CTC completion on medical injuries in ages 0-19 years (compared with 20-34 years) was not statistically significant (online supplementary appendix, table A5). A significant relative reduction in medical injuries in the age group $0-4$ years was observed in the implementation phase (1-4, compared with baseline).

\section{DISCUSSION}

This is the first study to evaluate the impact of CTC on injuries in children and young people and one of few to evaluate a community intervention's impact on youth hospital injury admissions. In keeping with the hypotheses, the study identified reductions in all injury admissions in children when communities were completing the first cycle of CTC (phase 5) and second cycle of CTC (phase 6) (table 4); however, depending on the methodology used, not all associations were statistically significant. The most pronounced effects were observed in the age group 0-4 years. A significant reduction was observed at phase 5 when using medical injury as reference group (ie, testing the relative effect of the CTC on community-acquired injuries vs medical injuries: table 5).

Pilot evaluations of the implementation of CTC in four Australian communities have indicated reductions in adolescent injury risk factors including alcohol and other drug use and behaviour problems. ${ }^{24}$ Although prior studies have evaluated CTC for impacts on injury risk factors, the current study is the first to evaluate effects on child and adolescent injuries. The findings of this study support the notion that while the CTC framework can be used to reduce alcohol and drug use and its associated risk factors, it could also simultaneously reduce hospital admission injuries. If systematically applied 
Table 4 Multivariate results of injuries for interaction between CTC phase and age group

\begin{tabular}{|c|c|c|c|c|c|c|c|c|}
\hline & \multicolumn{2}{|c|}{$\begin{array}{l}\text { Age } 0-4 \text { years }(r e f=20-34 \\
\text { years) }\end{array}$} & \multicolumn{2}{|c|}{$\begin{array}{l}\text { Age } 5-9 \text { years }(\text { ref }=20-34 \\
\text { years) }\end{array}$} & \multicolumn{2}{|c|}{$\begin{array}{l}\text { Age } 10-14 \text { years }(\mathrm{ref}=20-34 \\
\text { years) }\end{array}$} & \multicolumn{2}{|c|}{$\begin{array}{l}\text { Age } 15-19 \text { years }(r e f=20-34 \\
\text { years) }\end{array}$} \\
\hline & RR & $(95 \% \mathrm{Cl})$ & RR & $(95 \% \mathrm{Cl})$ & RR & $(95 \% \mathrm{Cl})$ & RR & $(95 \% \mathrm{Cl})$ \\
\hline \multicolumn{9}{|l|}{ All injury admissions } \\
\hline \multicolumn{9}{|l|}{ Phase (phase $0=$ ref) } \\
\hline Implementation (phase 1-4) & 1.05 & (0.97 to 1.13$)$ & 1.03 & (0.95 to 1.11$)$ & 1.05 & (0.98 to 1.12$)$ & 1.01 & (0.95 to 1.08$)$ \\
\hline Completion (phase 5) & 0.88 & (0.79 to 0.98$)$ & 0.91 & (0.80 to 1.02$)$ & 0.95 & (0.87 to 1.05$)$ & 0.99 & (0.90 to 1.08$)$ \\
\hline Second cycle (phase 6) & 0.76 & (0.69 to 0.83 ) & 0.88 & (0.80 to 0.96$)$ & 0.92 & $(0.86$ to 1.00$)$ & 0.90 & (0.84 to 0.98$)$ \\
\hline \multicolumn{9}{|l|}{ Unintentional injuries* } \\
\hline \multicolumn{9}{|l|}{ Phase (phase $0=$ ref) } \\
\hline Implementation (phase 1-4) & 1.02 & (0.94 to 1.10$)$ & 0.99 & (0.91 to 1.07 ) & 0.97 & (0.90 to 1.04$)$ & 0.98 & (0.91 to 1.05 ) \\
\hline Completion (phase 5) & 0.87 & (0.77 to 0.98$)$ & 0.90 & (0.80 to 1.03$)$ & 0.91 & (0.82 to 1.01$)$ & 0.97 & (0.87 to 1.08$)$ \\
\hline Second cycle (phase 6) & 0.74 & (0.67 to 0.81$)$ & 0.85 & (0.77 to 0.94$)$ & 0.90 & (0.83 to 0.97$)$ & 0.91 & (0.83 to 0.99 ) \\
\hline \multicolumn{9}{|l|}{ Transport injuries } \\
\hline \multicolumn{9}{|l|}{ Phase (phase $0=$ ref) } \\
\hline Implementation (phase 1-4) & 0.81 & (0.65 to 1.02$)$ & 0.95 & (0.81 to 1.12 ) & 1.01 & (0.89 to 1.15$)$ & 0.94 & (0.84 to 1.06$)$ \\
\hline Completion (phase 5) & 0.77 & (0.56 to 1.05$)$ & 0.91 & (0.75 to 1.10$)$ & 1.05 & (0.88 to 1.25$)$ & 1.13 & (0.96 to 1.33 ) \\
\hline Second cycle (phase 6) & 0.74 & (0.55 to 0.98$)$ & 0.81 & (0.68 to 0.96$)$ & 1.02 & (0.90 to 1.15$)$ & 1.11 & (0.99 to 1.24$)$ \\
\hline
\end{tabular}

Results are presented as incidence rate ratios, RR (the effect size of the interaction terms are exponentiated).

The parameter estimates are the interaction variable for CTC phase by age group, adjusted for age, sex, socioeconomic index for area remoteness and year. Results statistically significant at $p=0.05$ are shown in bold font.

*Sports injury are excluded.

CTC, Communities That Care.

to numerous municipalities, the framework could be used to substantially reduce the burden on healthcare and welfare systems. The current findings are particularly important as injuries are leading causes of mortality and morbidity in young people. ${ }^{3}$

Community coalitions that aim to reduce community injury rates operate in a number of countries. ${ }^{32} 33$ Similar to the CTC approach, ${ }^{17} 25$ these coalitions work across sectors and in a variety of settings to prevent and reduce injury. However, there is limited evidence for reduction of injury rates by such interventions as these often focus on removal of injury hazards and are poorly evaluated. The CTC coalition training is designed to expand local investment in evidence-based programme in schools, and family and community services. ${ }^{24-26}$ By repeating valid epidemiological child and youth surveys, CTC coalitions monitor and continually improve efforts to reduce injury risk factors including poor parenting, ${ }^{9}$ child behaviour problems, ${ }^{10}$ alcohol and other drug use ${ }^{11}$ and peer violence. ${ }^{6}$ Given that CTC is implemented using a common manualised approach, ${ }^{25}$

Table 5 Multivariate results for modelling the interaction between CTC phase and injury cause group: medical versus community

\begin{tabular}{lll}
\hline & \multicolumn{2}{l}{$\begin{array}{l}\text { Injury type=community injury (ref=medical } \\
\text { injury) }\end{array}$} \\
\cline { 2 - 3 } & RR & $(95 \% \mathrm{Cl})$ \\
\hline All injury admissions & & \\
\hline Phase (phase 0=ref) & 1 & (Ref) \\
Implementation (phase 1-4) & 1.00 & $(0.92$ to 1.09$)$ \\
Completion (phase 5) & 0.81 & $(0.73$ to 0.89$)$ \\
Second cycle (phase 6) & 0.91 & $(0.82$ to 1.01$)$ \\
\hline
\end{tabular}

The rate ratios are the exponentiated parameter estimates of the interaction variable for CTC phase by injury (medical vs community injury), adjusted for age, sex, socioeconomic index for area remoteness and year. Results statistically significant at $\mathrm{p}=0.05$ are shown in bold font.

CTC, Communities That Care. it is likely that the current findings could generalise to CTC implementation in other nations and jurisdictions. ${ }^{20} 34$ The current findings suggest that youth injury outcome measures should be incorporated into future CTC evaluations.

The CTC process uses a youth survey to identify priority prevention targets. ${ }^{24}$ Similarly, youth surveys have been advocated in instruments such as the Youth Risk Behaviour Surveillance System (www.cdc.gov/healthyyouth/data/yrbs/index. htm). These surveys have been used to guide injury intervention delivery in communities. Such surveys have also been important for monitoring and surveillance. However, if the findings of this study can be replicated, future research should examine the extent the CTC youth survey offers comparative advantages in guiding injury intervention, compared with other forms of monitoring and surveillance.

While the study did provide evidence of a reduction in hospital injury admissions, the exact mechanism as to how this may be achieved is not clear. The CTC process uses local data to identify local priorities. Based on this information, local communities develop their priorities and create their own action plan. ${ }^{17}$ While each community targeted alcohol and drug outcomes, a variety of different interventions were implemented across the various CTC sites. Some interventions such as reducing youth alcohol supply were common across communities, while the implementation of evidence-based school and parent programme varied by CTC community. ${ }^{24}$ The current finding of injury prevention effects for children aged $0-4$ years may arise through enhanced parent education and reduced behaviour problems and alcohol and drug use in older siblings. Future research should examine if there are specific interventions that contribute differentially to injury prevention.

Strengths of the current study include the use of a large epidemiologically valid injury database. While the nonexperimental design increases naturalistic (external) validity, a substantial limitation is that the phase 6 communities were 
not recruited in the randomised trial. This limitation increases the potential for factors such as community leadership to have contributed to injury prevention effects and may mean that the association is not a true secondary outcome of the CTC prevention approach. A further limitation is that the study used only coded admissions and no other source of injury data to cross validate injury reports. The study also did not examine variation in CTC programme implementation, which is likely to have impacted on both primary and secondary outcomes. Finally, the study was designed to identify relative effects by using reference groups: the completion phase versus baseline; children versus adults; and community injury versus medical injury. This relies on a specific effect of the CTC on the group of interest and no effect on the reference group. Given the CTC programme focus on alcohol and drug outcomes, it is likely that adults (and adult injury rates) were also affected. This may have led to an underestimate of the relative effect of the CTC on child injury in this study. Further research with larger sample sizes should investigate these factors.

Notwithstanding the limitations of this study, the findings provide the first evidence that there may be an association of the CTC community coalition approach and a reduction in youth injury hospital admissions. While the findings will need to be replicated, and stronger study designs, including testing of mediation models, should be employed, CTC coalition training as an intervention strategy for preventing youth injury hospital admissions is showing signs of promise.

\section{What is already known on the subject}

- Community coalitions that aim to reduce injury rates operate in several countries. There have been few evaluations of the effects of such interventions on rates of injury.

\section{What this study adds}

- This evaluation is the first to associate the Communities That Care coalition training process with reductions in hospital injury admissions in youth.

Contributors All authors contributed to the conceptualisation of the study, interpretation of the findings and drafting and revising of the manuscript.

Funding We acknowledge funding support from the National Health and Medical Research Council (APP1087781), Australian Research Council (LP100200755), State Government of Victoria (Department of Justice and Regulation, VicRoads and Transport Accident Commission) and lan Potter Foundation (GRANT ID 20170371).

Competing interests The following authors served in the not-for-profit company Communities That Care Ltd that was evaluated in this paper: Rowland (current chief executive officer (CEO)), Reavley, Minuzzo (directors) and Toumbourou (director and ex-CEO).

\section{Patient consent for publication Not required}

Ethics approval Victorian Injury Surveillance Unit has ethical approval for custody, use and dissemination of Victorian hospital data on injury (Monash University Human Ethics Committee project 21427).

Provenance and peer review Not commissioned; externally peer reviewed. Data availability statement Data are available on reasonable request.

Open access This is an open access article distributed in accordance with the Creative Commons Attribution Non Commercial (CC BY-NC 4.0) license, which permits others to distribute, remix, adapt, build upon this work non-commercially, and license their derivative works on different terms, provided the original work is properly cited, appropriate credit is given, any changes made indicated, and the use is non-commercial. See: http://creativecommons.org/licenses/by-nc/4.0/.

ORCID ID
Janneke Berecki-Gisolf http://orcid.org/0000-0002-5035-3547

\section{REFERENCES}

1 Mokdad AH, Forouzanfar MH, Daoud F, et al. Global burden of diseases, injuries, and risk factors for young people's health during 1990-2013: a systematic analysis for the global burden of disease study 2013. The Lancet 2016;387:2383-401.

2 Hayman J, Berecki-Gisolf J. Unintentional Hospital treated injury Victoria, 2018.

3 WHO. World report on child injury prevention. Geneva: World Health Organization, 2008

4 Toumbourou JW, Olsson CA, Rowland B, et al. Health psychology intervention in key social environments to promote adolescent health. Aust Psychol 2014;49:66-74.

5 Poulos R, Hayen A, Finch C, et al. Area socioeconomic status and childhood injury morbidity in New South Wales, Australia. Injury Prevention 2007;13:322-7.

6 Djerboua M, Chen BE, Davison CM. Physical fighting, fighting-related injuries and family affluence among Canadian youth. BMC Public Health 2016;16:199.

7 Olsen $\mathrm{H}$, Kennedy E. Safety of school Playgrounds: field analysis from a randomized sample. The Journal of School Nursing; 131 .

8 Abt TP. Towards a framework for preventing community violence among youth. Psychol Health Med 2017;22:266-85.

9 Kendrick D, Mulvaney CA, Ye L, et al. Parenting interventions for the prevention of unintentional injuries in childhood. Cochrane Database Syst Rev 2013;36.

10 Bussing R, Menvielle E, Zima B. Relationship between behavioral problems and unintentional injuries in US children: findings of the 1988 National health interview survey. JAMA Pediatrics 1996;150:50-6.

11 Dinh MM, Bein KJ, Roncal S, et al. The impact of alcohol intoxication in patients admitted due to assault at an Australian major trauma centre: a trauma registry study from 1999 to 2009. Emerg Med J 2014:31:390-3.

12 Gutjahr E, Gmel G, Rehm J. Relation between average alcohol consumption and disease: an overview. Eur Addict Res 2001;7:117-27.

13 Rehm J, Room R, Taylor B. Method for moderation: measuring lifetime risk of alcoholattributable mortality as a basis for drinking guidelines. Int J Methods Psychiatr Res 2008; $17: 141-51$

14 Toumbourou JW, Kypri K, Jones SC, et al. Should the legal age for alcohol purchase be raised to 21? Medical Journal of Australia 2014;200:568-70.

15 Toumbourou JW, Stockwell T, Neighbors C, et al. Interventions to reduce harm associated with adolescent substance use. The Lancet 2007:369:1391-401.

16 Loxley W, Toumbourou JW, Stockwell T, et al. The prevention of substance use, risk and harm in Australia: A review of the evidence. Canberra: Commonwealth of Australia, 2004.

17 Hawkins JD, Oesterle S, Brown EC, et al. Results of a type 2 translational research trial to prevent adolescent drug use and delinquency. Arch Pediatr Adolesc Med 2009;163:789-98.

18 Spinks A, Turner C, Nixon J, et al. The 'WHO Safe Communities' model for the prevention of injury in whole populations. Cochrane Database Syst Rev 2009;3.

19 McMorris BJ, Hemphill SA, Toumbourou JW, et al. Prevalence of substance use and delinquent behavior in adolescents from Victoria, Australia and Washington state, United States. Health Educ Behav 2007:34:634-50.

20 Toumbourou JW, Hemphill SA, McMorris BJ, et al. Alcohol use and related harms in school students in the USA and Australia. Health Promot Int 2009:24:373-82.

21 Prevention NC. Pathways to prevention: Developmental and early intervention approaches to crime in Australia. Canberra.: Commonwealth Attorney Generals Department, 1999

22 Toumbourou JW. Mobilising Commuities to prevent youth problems including homelessness and substance abuse. Parity 1999;12.

23 Toumbourou JW. Implementing Communities That Care in Australia: A community mobilisation approach to crime prevention. Canberra, Australia: Australian Institute of Criminology, 1999

24 Toumbourou JW, Rowland B, Williams J, et al. Community intervention to prevent adolescent health behavior problems: evaluation of communities that care in Australia. Health Psychology 2019:38:536-44.

25 Quinby RK, Hanson K, Brooke-Weiss B, et al. Installing the communities that care prevention system: implementation progress and fidelity in a randomized controlled trial. J Community Psychol 2008;36:313-32.

26 Rowland B, Abraham C, Carter R, et al. Trial protocol: a clustered, randomised, longitudinal, type 2 translational trial of alcohol consumption and alcohol-related harm among adolescents in Australia. BMC Public Health 2018;18:559.

27 ABS. Australian statistical geography standard (ASGS), 2019. Available: https://www. abs.gov.au/websitedbs/D3310114.nsf/home/Australian+Statistical+Geography+ Standard+(ASGS) [Accessed 10 Jun 2019].

28 Hayman J. Berecki-Gisolf J. E-bulletin Edition 19. Unintentional (accidental) hospitaltreated injury Victoria, 2017/18. Melbourne, Victoria: Victorian Injury Surveillance Unit, Monash University, 2019.

29 ABS. Socio-economic indexes for areas (SEIFA). Canberra, ACT: Australian Bureau of Statistics;2011. 2033.0.55.001 - Socio-economic Indexes for Areas (SEIFA), Data Cube only, 2011

30 ABS. Review of the rural, remote, and metropolitan areas (RRMA) classification. Canberra, ACT: Australian Government Department of Health \& Ageing, 2005. 
31 Hayman J, Berecki-Gisolf J. Unintentional Hospital treated injury Victoria, 2016/17. Victorian Injury Surveillance Unit. Monash University Accident Research Centre, 2018.

32 Sellström Eet al. Association between childhood community safety interventions and hospital injury records: a multilevel study. Journal of Epidemiology \& Community Health 2003;57:724-9.
33 Pressley JC, Barlow B, Durkin M, et al. A national program for injury prevention in children and adolescents: the injury free coalition for kids. J Urban Health 2005;82:389-402.

34 Glaser RR, Horn MLV, Arthur MW, et al. Measurement properties of the communities that Care $₫$ youth survey across demographic groups. J Quant Criminol 2005;21:73-102. 